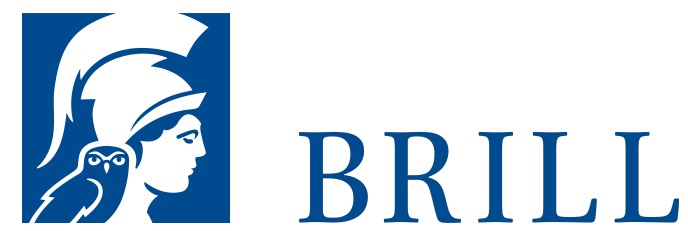

\title{
Transnacionalidad e hibridez en el ensayo hispánico
}

Un género sin orillas

Volume Editors: Reindert Dhondt and Dagmar Vandebosch

Transnacionalidad e hibridez en el ensayo hispánico. Un género sin orillas examines how the essay, a privileged genre for the articulation of national identities in Latin America and Spain for decades, is being reconfigured in the present age of globalisation and transnationalisation. The articles included in this volume pay particular attention to the discursive forms and the practices of publishing that question old national categories, without disregarding their relevance.

Starting from some theoretical considerations about the contemporary Latin American essay, the book concentrates especially on three dimensions of transnationalising the essay: the experience of exile, the tensions between the national and the transnational in the redefinition of Hispanic identities, and its relation with the genre's formal hybridisation, in the work of authors such as Bolaño, Piglia and Vila-Matas.

Transnacionalidad e hibridez en el ensayo hispánico. Un género sin orillas estudia cómo el ensayo, que durante décadas ofreció un foro privilegiado a la articulación de identidades nacionales en Latinoamérica y España, se está reconfigurando en una era de globalización y transnacionalización. Este volumen dedica atención especial a las formas discursivas y los modos de publicación que ponen en entredicho las antiguas categorías nacionales, sin descartar la relevancia de éstas.

Partiendo

See More

Readership

All concerned with the Hispanic essay and essayistic discourse as such, as well as anyone interested in transnationality, exile, genre hybridity or the impact of digital technologies on essayistic writing.

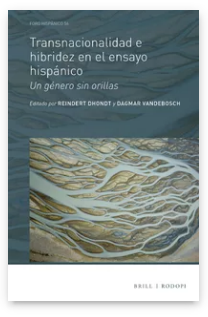

Pages: Approx. $300 \mathrm{pp}$.

Language:

Spanish

Subjects:

Hispanic

Studies,

Literature and

Cultural Studies,

Criticism \&

Theory,

Literature and

Cultural Studies,

Global Studies,

Social Sciences,

Latin America,

American

Studies

Publisher: Brill

Series:

Foro Hispánico,

Volume: $5^{6}$

E-Book (PDF)

Released online:

o1 Nov 2016

ISBN: 978-90-

04-33049-8

List price

USD \$151.00

Hardback

Publication date:

10 Nov 2016 
ensayístico en general, así como en la transnacionalidad, el exilio, la hibridez genérica o el impacto de las tecnologías digitales sobre la escritura ensayística.

ISBN: $978-90-$

04-33047-4

List price

USD $\$ 151.00$ 
Reindert Dhondt is assistant professor of Hispanic Literature at Utrecht University. He has previously worked at Leuven University, Brown University and UCLA. He is author of Carlos Fuentes y el pensamiento barroco (2015) and has edited International Don Quixote (with Theo D'haen, 2009). He is particularly interested in essayistic discourse in Latin America and the interrelation between violence and literature in Mexico.

Dagmar Vandebosch is associate professor of Hispanic literatures at Leuven University. Her scientific interests and academic publications focus on Hispanic literature in intercultural and transnational contexts, with a specific interest in the essay. She most recently edited El juego con los estereotipos (Peter Lang, 2012) and Ensayo hispánico y sociedad: Diálogos de un género en movimiento (Droz, 2014).

Reindert Dhondt es profesor de literaturas hispánicas en la Universidad de Utrecht. Ha sido investigador posdoctoral en la Universidad de Lovaina (KU Leuven), donde se doctoró, e investigador visitante en UCLA, Brown University y la UNAM. Es autor de Carlos Fuentes y el pensamiento barroco (Iberoamericana/Vervuert, 2015), así como coeditor de un volumen sobre Cervantes (International Don Quixote, Rodopi, 2009, con Theo D'haen). En la actualidad, se dedica al discurso ensayístico en América Latina y a la interrelación entre violencia y literatura en México.

Dagmar Vandebosch es profesora de literaturas hispánicas en la Universidad de Lovaina (KU Leuven). Sus intereses científicos se centran en la literatura hispánica en contextos interculturales y transnacionales, con un interés específico en el ensayo. Es autora de Y no con el lenguaje preciso de la ciencia. La ensayística de Gregorio Marañón en la entreguerra española (Droz, 2006) y coeditora de los volúmenes El juego con los estereotipos (Peter Lang, 2012), El ensayo hispánico: Cruces de géneros, síntesis de formas, y Ensayo hispánico y sociedad: Diálogos de un género en movimiento (Droz, 2012 y 2014).

For more information see brill.com 
Titles published by Brill | Fink, Brill | mentis or Brill | Schöningh: +49(o)71 5413279216 | brill@brocom.de 